Check for updates

Cite this: RSC Adv., 2018, 8, 36392

Received 31st August 2018

Accepted 12th October 2018

DOI: $10.1039 / \mathrm{c} 8 \mathrm{ra07256f}$

rsc.li/rsc-advances

\section{Synthesis of benzo[4,5]imidazo[1,2-a]pyrimidines and 2,3-dihydroquinazolin-4(1H)-ones under metal-free and solvent-free conditions for minimizing waste generation $\dagger$}

\author{
Phuong Hoang Tran, (D) * Thanh-Phuong Thi Bui, Xuan-Quynh Bach Lam \\ and Xuan-Trang Thi Nguyen
}

Brønsted acidic ionic liquid was found to be an efficient and recyclable catalyst for the synthesis of benzo [4,5]imidazo[1,2-a]pyrimidines and 2,3-dihydroquinazolin-4(1H)-ones. The reactions proceeded smoothly with a broad scope of substrates providing the expected products in good to excellent yields under an atom-economical pathway. The low-cost recyclable catalyst, metal- and solvent-free conditions, and the ease of product isolation are the highlighted advantages in solving the issue of trace metal contamination in synthesized pharmaceuticals.

\section{Introduction}

The invention of new catalysts for the synthesis of biologically active compounds is essential to the advancement of green chemistry. ${ }^{1-3}$ Classical aqueous inorganic acids including $\mathrm{H}_{2} \mathrm{SO}_{4}, \mathrm{HF}, \mathrm{HCl}, \mathrm{HNO}_{3}$, and $\mathrm{H}_{3} \mathrm{PO}_{4}$ have been used for various organic transformations. Nevertheless, these homogeneous Brønsted acids are not suitable for widespread application due to separation and environmental issues. ${ }^{4}$ Ionic liquids have attracted considerable attention in many fields due to their structural diversity, low cost, and low toxicity. ${ }^{5-7}$ The use of ionic liquids as green catalysts for chemical reactions has presented many advantages in a sustainable synthesis. ${ }^{8-13}$ These homogeneous catalysts are thermally stable, highly active, and easily recyclable. ${ }^{14}$ The most popular Brønsted acidic ionic liquids have been easily prepared by the reaction of 1,4-butane sultone or 1,3-propane sultone with $N$-methylimidazole. ${ }^{15}$ Thus, these Brønsted acidic ionic liquids have been widely used as green catalysts for various organic transformations. ${ }^{16-24}$ Herein, we report the synthesis of benzo[4,5]imidazo[1,2-a]pyrimidines and 2,3-dihydroquinazolin-4(1H)-ones catalyzed by a Brønsted acidic ionic liquid under solvent-free conditions. The presented method is considered an essential solution for the environmental problems in industrial processes. The current synthesis scheme contributes to the sustainable and low-cost pathway for the preparation of benzo[4,5]imidazo[1,2-a]pyrimidines and 2,3-dihydroquinazolin-4(1H)-ones.

Department of Organic Chemistry, Faculty of Chemistry, University of Science, Viet Nam National University, Ho Chi Minh City 721337, Viet Nam. E-mail: thphuong@ hcmus.edu.vn; Tel: +84903706762

$\dagger$ Electronic supplementary information (ESI) available. See DOI: $10.1039 / \mathrm{c} 8 \mathrm{ra} 07256 \mathrm{f}$

\section{Results and discussion}

\section{Synthesis of benzo[4,5]imidazo[1,2-a]pyrimidines}

Pyrimidine derivatives are backbones of various pharmaceutical drugs with various applications including anticancer, ${ }^{25-29}$ antiinflammatory, ${ }^{30-32}$ antibacterial, ${ }^{31,33-35}$ and antifungal activities. ${ }^{35-37}$ Over the past decade, many approaches have been achieved for the preparation of pyrimidine derivatives. ${ }^{38-42}$ However, multi-step or low-yield procedures and harmful conditions could limit the widespread use of these approaches. Recently, multicomponent reactions have provided new prospects for the advancement in organic synthesis to eliminate these drawbacks. ${ }^{43,44}$ Herein, the Brønsted acidic ionic liquid was used for the first time to catalyze the synthesis of benzo[4,5] imidazo[1,2-a]pyrimidines via a one-pot multicomponent reaction. Initially, $\left[\left(4-\mathrm{SO}_{3} \mathrm{H}\right) \mathrm{BMIM} \mathrm{HSO}_{4}\right.$ ionic liquid was prepared as reported in the literature. ${ }^{22}$ The structure of [(4- $\left.\left.\mathrm{SO}_{3} \mathrm{H}\right) \mathrm{BMIM}\right]$ $\mathrm{HSO}_{4}$ was confirmed by NMR, FT-IR, TGA, and HR-MS (ESI, Section $\mathrm{S} 2 \dagger)$. The as-synthesized $\left[\left(4-\mathrm{SO}_{3} \mathrm{H}\right) \mathrm{BMIM}\right] \mathrm{HSO}_{4}$ was obtained in high yield after a simple purification step. Thermogravimetric analysis shows that $\left[\left(4-\mathrm{SO}_{3} \mathrm{H}\right) \mathrm{BMIM}\right] \mathrm{HSO}_{4}$ is thermally stable (up to $250^{\circ} \mathrm{C}$ ). Next, we investigated the model reaction between 2-aminobenzimidazole, ethyl acetoacetate, and benzaldehyde in the presence of different catalysts $(10 \mathrm{~mol} \%)$ at $100{ }^{\circ} \mathrm{C}$ for $120 \mathrm{~min}$ (Table 1$)$. When the model reaction was performed using metal chlorides such as $\mathrm{AlCl}_{3}$, $\mathrm{FeCl}_{3}, \mathrm{FeCl}_{2}$, and $\mathrm{ZnCl}_{2}$ as the catalysts at $100{ }^{\circ} \mathrm{C}$ for $120 \mathrm{~min}$, the expected product was obtained in $32 \%$ to $60 \%$ yield (Table 1 , entries 1-4). These results encouraged us to test a series of Lewis acidic deep eutectic solvents with zinc chloride. However, the yields of the desired product drastically decreased (Table 1, entries 5-7). Other deep eutectic solvents were investigated by 
Table 1 Yields for reaction of 2-aminobenzimidazole, ethyl acetoacetate, and benzaldehyde with different catalysts ${ }^{a}$

\begin{tabular}{|c|c|c|}
\hline Entry & Catalyst & Yield $^{b}(\%)$ \\
\hline 1 & $\mathrm{AlCl}_{3}$ & 57 \\
\hline 2 & $\mathrm{FeCl}_{3}$ & 60 \\
\hline 3 & $\mathrm{FeCl}_{2}$ & 32 \\
\hline 4 & $\mathrm{ZnCl}_{2}$ & 60 \\
\hline 5 & {$[$ CholineCl $][\mathrm{ZnCl}]$} & 0 \\
\hline 6 & {$[$ CholineCl $][\mathrm{ZnCl}]_{2}$} & 22 \\
\hline 7 & {$[$ CholineCl $][\mathrm{ZnCl}]_{3}$} & 12 \\
\hline 8 & {$[\text { CholineCl] [ethylene glycol }]_{2}$} & 59 \\
\hline 9 & [CholineCl][glucose] & 48 \\
\hline 10 & {$[$ CholineCl $][\text { oxalic acid }]_{2}$} & 52 \\
\hline 11 & [EMIM]Cl & 67 \\
\hline 12 & {$[\mathrm{BMIM}] \mathrm{BF}_{4}$} & 69 \\
\hline 13 & {$\left[\left(4-\mathrm{SO}_{3} \mathrm{H}\right) \mathrm{BMIM}\right] \mathrm{HSO}_{4}$} & 89 \\
\hline
\end{tabular}

${ }^{a}$ Reaction condition: 2-aminobenzimidazole $(1.0 \mathrm{mmol})$, ethyl acetoacetate $(1.0 \mathrm{mmol})$, benzaldehyde $(1.0 \mathrm{mmol})$, and catalyst $(10 \mathrm{~mol} \%)$ at $100{ }^{\circ} \mathrm{C}$ for $120 \mathrm{~min} .{ }^{b}$ Isolated yield.

replacing $\mathrm{ZnCl}_{2}$ with ethylene glycol, oxalic acid or glucose (Table 1, entries 8-10), but the yields of the product were not satisfactory. Thus, we focused on ionic liquids. Three types of ionic liquids, namely, [EMIM]Cl, $[\mathrm{BMIM}] \mathrm{BF}_{4}$, and $\left[\left(4-\mathrm{SO}_{3} \mathrm{H}\right)\right.$ $\mathrm{BMIM}] \mathrm{HSO}_{4}$, were tested for the model reaction. When the reactions were performed in ionic liquid media, the yields of the desired product drastically increased (Table 1, entries 11-13). Among these ionic liquids, $\left[\left(4-\mathrm{SO}_{3} \mathrm{H}\right) \mathrm{BMIM}\right] \mathrm{HSO}_{4}$ showed the best efficiency, allowing the reaction to afford $89 \%$ yield (Table 1, entry 13). As shown in Table 1 , metal chlorides could be employed in the model reaction. However, these metal chlorides are moisture sensitive and easily decompose in the presence of a small amount of water. Furthermore, these metal chlorides could not be recovered and reused after the aqueous

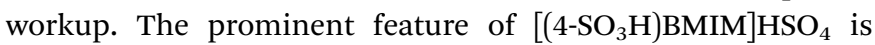
stability in water and in almost all cases, catalytic use, recovery,

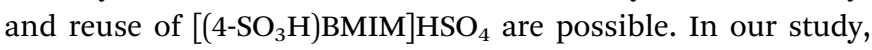
we tested different ratios of $\left[\left(4-\mathrm{SO}_{3} \mathrm{H}\right) \mathrm{BMIM}\right] \mathrm{HSO}_{4}$ with the aim of obtaining the desired product in high yield. The best yield was obtained in the presence of $10 \mathrm{~mol} \%\left[\left(4-\mathrm{SO}_{3} \mathrm{H}\right) \mathrm{BMIM}^{2} \mathrm{HSO}_{4}\right.$. When the amount of catalyst was increased to $15 \mathrm{~mol} \%$, the yield slightly improved. All attempts to reduce the amount of $\left[\left(4-\mathrm{SO}_{3} \mathrm{H}\right) \mathrm{BMIM}\right] \mathrm{HSO}_{4}$ loading led to diminished yields.

With the optimized conditions in hand, we focused on using a variety of aromatic aldehydes. The results are presented in Scheme 1. A series of $p$-substituted benzaldehyde smoothly reacted with 2-aminobenzimidazole and ethyl acetoacetate to provide benzo[4,5]imidazo[1,2-a]pyrimidines in excellent yields. Electron-donating group on benzaldehyde, such as methoxybenzaldehyde, gave the expected products in excellent yield (90\%), but longer reaction time was required (150 $\mathrm{min})$. Electron-withdrawing groups on benzaldehyde, such as 2nitrobenzaldehyde and 4-nitrobenzaldehyde, were all effectively reactive and provided the corresponding products in excellent yields within shorter reaction times $(75 \mathrm{~min})$. Benzaldehyde bearing halogen substituents could also react smoothly to attain the expected products in high yields (88-92\%), and the substituent position did not significantly affect the reaction yield. In the interest of extending the scope of reaction, we examined acetonylacetone under the current method. To our delight, the reactions proceed smoothly to provide the desired products in high yields (88-93\%) and shorter reaction times (60-90 $\mathrm{min}$ ). Moreover, the method avoids the use of volatile organic solvents, harmful conditions, and additives making it greener than the previous reports. In addition, the pure products were obtained easily by recrystallization; thus, this method shows promise for application in industry.

The comparison of the present method with previously reported literature is shown in Table 2. The multicomponent reaction of 2-aminobenzimidazole, ethyl acetoacetate, and benzaldehyde in the presence of $\left[\left(4-\mathrm{SO}_{3} \mathrm{H}\right) \mathrm{BMIM}\right] \mathrm{HSO}_{4}$ afforded the expected product in good yield within $2 \mathrm{~h}$ under metal-free and solvent-free conditions (Table 2, entry 6 ). The previous studies reported that the same reaction also achieved the target products in moderate to good yields, but some methods required longer reaction time and/or high temperature (Table 2, entries, 1-5). More importantly, the $\left[\left(4-\mathrm{SO}_{3} \mathrm{H}\right) \mathrm{BMIM}^{-} \mathrm{HSO}_{4}\right.$ could be recovered and reused without any considerable loss in catalytic activity in a test of six cycles of reuse.

To get more information about the plausible mechanism, we performed three control experiments under the optimized conditions. 2-Benzylidene-3-oxobutanoate intermediate was detected as the major product (by GC-MS) when the model reaction was performed for $20 \mathrm{~min}$. Thus, the reaction mainly followed Knoevenagel condensation between benzaldehyde and ethyl acetoacetate in the first step, where the $\left[\left(4-\mathrm{SO}_{3} \mathrm{H}\right) \mathrm{BMIM}\right]$ $\mathrm{HSO}_{4}$ acted as a Brønsted acidic catalyst. The control experiments with only two components, i.e., the reaction of benzaldehyde with ethyl acetoacetate, also provided the desired product (2-benzylidene-3-oxobutanoate) in $70 \%$ yield, which was higher than the reaction yield of 2-aminobenzimidazole and benzaldehyde. The intermediate could completely convert into the desired product when 2-aminobenzimidazole was added. Based on the above control experiments and previous literature, the plausible mechanism is proposed, as presented in Scheme 2. The reaction first followed Knoevenagel condensation between benzaldehyde and ethyl acetoacetate to produce 2-benzylidene-3-oxobutanoate as intermediate, which could further react with 2-aminobenzimidazole through Michael reaction. Finally, the desired product was obtained through cyclization and dehydration. The $\left[\left(4-\mathrm{SO}_{3} \mathrm{H}\right) \mathrm{BMIM}\right] \mathrm{HSO}_{4}$ played a vital role in four steps of the reaction.

\section{Synthesis of 2,3-dihydroquinazolin-4(1H)-ones}

Quinazolinones are valuable bioactive compounds possessing antitumor, ${ }^{45-47}$ antiviral, ${ }^{48,49}$ antibacterial, ${ }^{50,51}$ and antiinflammatory activities. ${ }^{52,53}$ Traditionally, both homogeneous and heterogeneous acidic catalysts can catalyze the synthesis of 2,3-dihydroquinazolin-4(1H)-ones. ${ }^{54-56}$ Recently, various protocols have been reported for the preparation of 2,3-dihydroquinazolin-4(1H)-ones with the aid of improving the reaction efficiency ${ }^{57-61}$ Moreover, 2,3-dihydroquinazolin-4(1H)- 


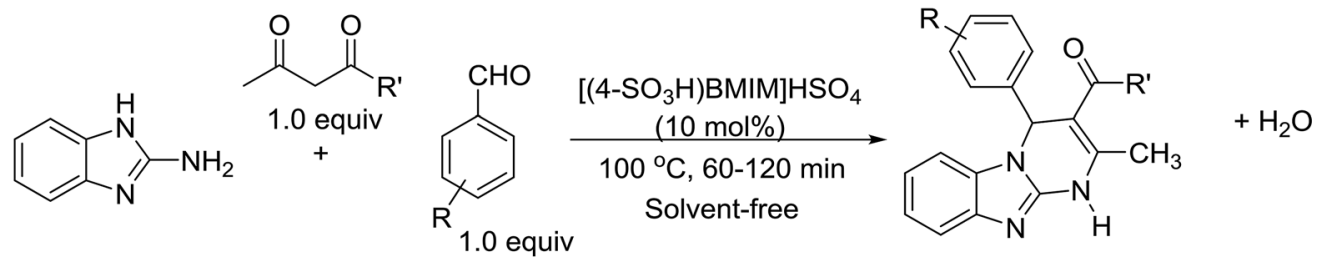<smiles>CCOC(=O)C1=C(C)Nc2nc3ccccc3n2C1c1ccccc1</smiles><smiles>CCOC(=O)C1=C(C)Nc2nc3ccccc3n2C1c1ccc(OC)cc1</smiles><smiles>CCOC(=O)C1=C(C)Nc2nc3ccccc3n2C1c1ccc(F)cc1</smiles><smiles>CCOC(=O)C1=C(C)Nc2nc3ccccc3n2C1c1ccc(Cl)cc1</smiles>

$89 \%, 120 \mathrm{~min}$

90\%, $150 \mathrm{~min}$

$89 \%, 90 \mathrm{~min}$

$89 \%, 90 \mathrm{~min}$

$\mathrm{NO}_{2}$<smiles>CCOC(=O)C1=C(C)Nc2nc3ccccc3n2C1c1ccc(F)cc1</smiles><smiles>CCOC(=O)C1=C(C)Nc2nc3ccccc3n2C1c1cccc(Cl)c1</smiles><smiles>CCOC(=O)C1=C(C)Nc2nc3ccccc3n2C1c1ccccc1F</smiles>
$92 \%, 75 \mathrm{~min}$ $88 \%, 90$ min $88 \%, 90$ min<smiles>CCOC(=O)C1=C(C)Nc2nc3ccccc3n2C1c1ccccc1Cl</smiles><smiles></smiles><smiles>CCOC(=O)C1=C(C)Nc2nc3ccccc3n2C1c1ccc2c(c1)OCO2</smiles><smiles>CC(=O)C1=C(C)Nc2nc3ccccc3n2C1c1ccccc1</smiles><smiles>O=[N+]=[No]</smiles><smiles>CC(=O)C1=C(C)Nc2nc3ccccc3n2C1c1ccccc1Cl</smiles><smiles></smiles>

$88 \%, 90 \mathrm{~min}$

$90 \%, 60 \mathrm{~min}$<smiles>COc1ccc(C2C(C(C)=O)=C(C)Nc3nc4ccccc4n32)cc1</smiles>

$88 \%, 120 \mathrm{~min}$<smiles>CC(=O)C1=C(C)Nc2nc3ccccc3n2C1c1ccc(F)cc1</smiles>

$93 \%, 60 \mathrm{~min}$<smiles>CC(=O)C1=C(C)Nc2nc3ccccc3n2C1c1ccc(F)cc1</smiles>

$91 \%, 90 \mathrm{~min}$<smiles>CC(=O)C1=C(C)Nc2nc3ccccc3n2C1c1ccc(Cl)cc1</smiles><smiles>CC(=O)C1=C(C)Nc2nc3ccccc3n2C1c1cccc(Cl)c1</smiles><smiles>CC(=O)C1=C(C)Nc2nc3ccccc3n2C1c1ccccc1F</smiles>

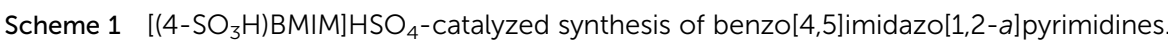

ones have been successfully synthesized using ionic liquids including [BMIM] $\mathrm{BF}_{4},{ }^{62}$ poly(4-vinylpyridine) supported acidic ionic liquids, ${ }^{63}$ and imidazolium triflate. ${ }^{64}$ However, methods that involved these ionic liquids presented some drawbacks, including high temperature, prolonged reaction time, and the use of volatile organic solvents. In this study, we report that [(4-
$\left.\left.\mathrm{SO}_{3} \mathrm{H}\right) \mathrm{BMIM}\right] \mathrm{HSO}_{4}$ acidic ionic liquid could be used as an active catalyst for the preparation of 2,3-dihydroquinazolin-4(1H)-ones presumably due to strong effect of Brønsted acidic groups on the ionic liquid. Interestingly, various aromatic aldehydes reacted successfully under the optimized conditions, and the expected product was obtained in excellent yields in the 
Table 2 Comparison of the present method with previous literature for the one-pot multicomponent synthesis of benzo[4,5]imidazo[1,2-a] pyrimidine<smiles>CCOC(=O)CC(C)CCCCCCOC(=O)C=O</smiles>

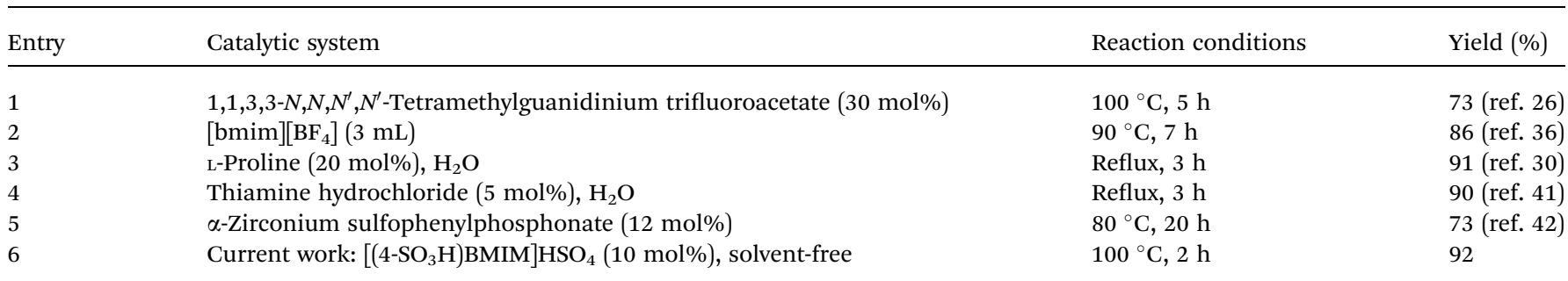

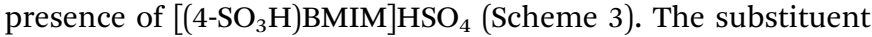
on the benzene did not affect the reaction rate. In addition, pure products were obtained easily by recrystallization. Remarkably, the condensation between anthranilamide and benzaldehyde was successfully performed on a $50 \mathrm{mmol}$ scale, and the expected yield was obtained equally with $1 \mathrm{mmol}$ scale. This method avoids the use of volatile organic solvents, harmful conditions, and metal catalysts, thus showing promise for application in industrial processes.

The comparison of the presented method with previously reported literature is shown in Table 3. The reaction of anthranilamide and benzaldehyde in the presence of $\left[\left(4-\mathrm{SO}_{3} \mathrm{H}\right)\right.$

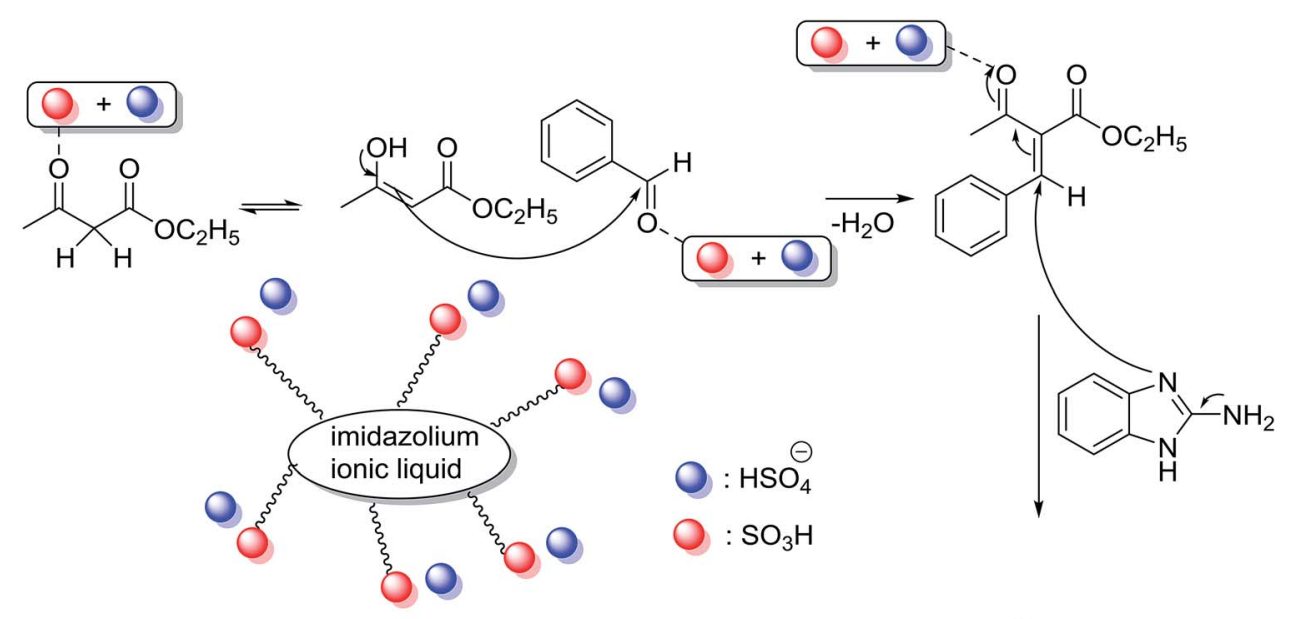<smiles>C=CC(=O)OCC(C)(C)C(C(=O)OCC)C(c1ccccc1)n1c(N)nc2ccccc21</smiles>

Scheme 2 Proposed mechanism for the preparation of benzo[4,5]imidazo[1,2-a]pyrimidines. 


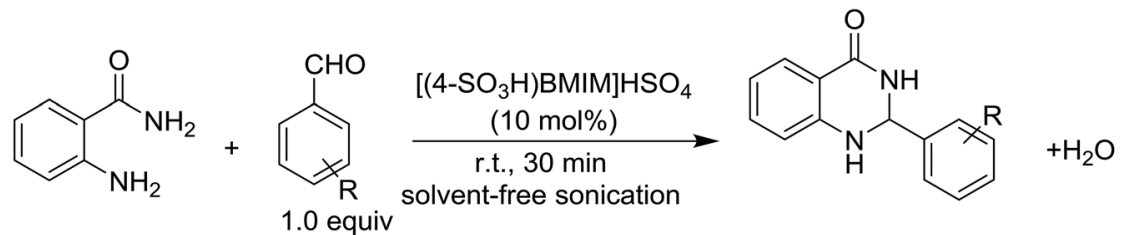<smiles>O=C1NC(c2ccccc2)Nc2ccccc21</smiles><smiles>O=C1NC(c2ccc(Cl)cc2)Nc2ccccc21</smiles><smiles>C=CC(=O)OCc1ccc(C)cc1</smiles><smiles>COc1ccc(C2NC(=O)c3ccccc3N2)cc1</smiles><smiles>O=C1NC(C2CCCCC2)Nc2ccccc21</smiles><smiles>O=C1NC(c2ccc(F)cc2)Nc2ccccc21</smiles><smiles>O=C1NC(c2ccc(O)cc2)Nc2ccccc21</smiles><smiles>CC(C)(C)c1ccc(C2NC(=O)c3ccccc3N2)cc1</smiles>

Scheme 3 Reaction scope with aldehydes.

BMIM] $\mathrm{HSO}_{4}$ afforded the expected product in excellent yield at room temperature for $30 \mathrm{~min}$ under metal-free and solvent-free conditions (Table 3, entry 6). The previous studies reported that the same reaction also achieved the target products in good to excellent yields, but some methods required the use of a solvent, high temperature and/or longer reaction time (Table 3 , entries, $1-5)$. Additionally, the $\left[\left(4-\mathrm{SO}_{3} \mathrm{H}\right) \mathrm{BMIM}\right] \mathrm{HSO}_{4}$ could be recovered and reused without any considerable loss of catalytic activity in a test of six cycles.

On the basis of our experiments and the literature, we proposed the reaction mechanism for the cyclocondensation between anthranilamide and aromatic aldehydes (Scheme 4). ${ }^{56,69}$ The first step could be the formation of imine as a critical intermediate under the presence of [(4- $\left.\left.\mathrm{SO}_{3} \mathrm{H}\right) \mathrm{BMIM}\right]$ $\mathrm{HSO}_{4}$. Next, the imine would be activated by the Brønsted acidic ionic liquid and the desired product could be obtained from the intermediate by the intramolecular nucleophilic attack of the nitrogen $\left(-\mathrm{NH}_{2}\right)$ on the amide group to imine carbon.

Recyclability of the catalyst is a necessary feature for theapplication in industrial processes. The recyclability of $\left[\left(4-\mathrm{SO}_{3} \mathrm{H}\right) \mathrm{BMIM}\right] \mathrm{HSO}_{4}$ in this study was investigated in the model reactions with benzaldehyde under optimal conditions (Fig. 1). After completion of the reaction, the reaction mixture was diluted with ethanol, and the desired product was obtained by filtration. The catalyst was recovered, dried under vacuum for $6 \mathrm{~h}$ and reused for next cycles. The yields of the product slightly decreased after the sixth cycle. The FT-IR spectra confirmed that there was no change in functional

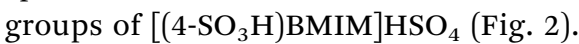

Table 3 Comparison of the presented method with previous literature for the synthesis of 2-phenyl-2,3-dihydroquinazolin-4(1H)-one<smiles>NC(=O)c1ccccc1N</smiles>

\begin{tabular}{|c|c|c|c|}
\hline Entry & Catalytic system & Reaction conditions & Yield (\%) \\
\hline 1 & {$[\mathrm{BMIM}] \mathrm{PF}_{6}(3.0 \mathrm{~mL})$} & $75{ }^{\circ} \mathrm{C}, 35 \mathrm{~min}$ & 89 (ref. 62) \\
\hline 2 & $\mathrm{Cp}_{2} \mathrm{TiCl}_{2}(1 \mathrm{~mol} \%)$, ethanol $(0.5 \mathrm{~mL})$ & $30{ }^{\circ} \mathrm{C}, 8 \mathrm{~min}$ & 96 (ref. 65) \\
\hline 4 & MNPs/DETA-SA $(15 \mathrm{mg}), \mathrm{H}_{2} \mathrm{O}(2.0 \mathrm{~mL})$ & $90^{\circ} \mathrm{C}, 40 \mathrm{~min}$ & 94 (ref. 67) \\
\hline 5 & $p$-Sulfonic acid calix[4]arene $(1.0 \mathrm{~mol} \%), \mathrm{H}_{2} \mathrm{O}(1.0 \mathrm{~mL})$ & r.t., $18 \mathrm{~min}$ & 94 (ref. 68) \\
\hline 6 & Current work: $\left[\left(4-\mathrm{SO}_{3} \mathrm{H}\right) \mathrm{BMIM}\right] \mathrm{HSO}_{4}(10 \mathrm{~mol} \%)$, solvent-free & r.t., $30 \mathrm{~min}$ & 98 \\
\hline
\end{tabular}




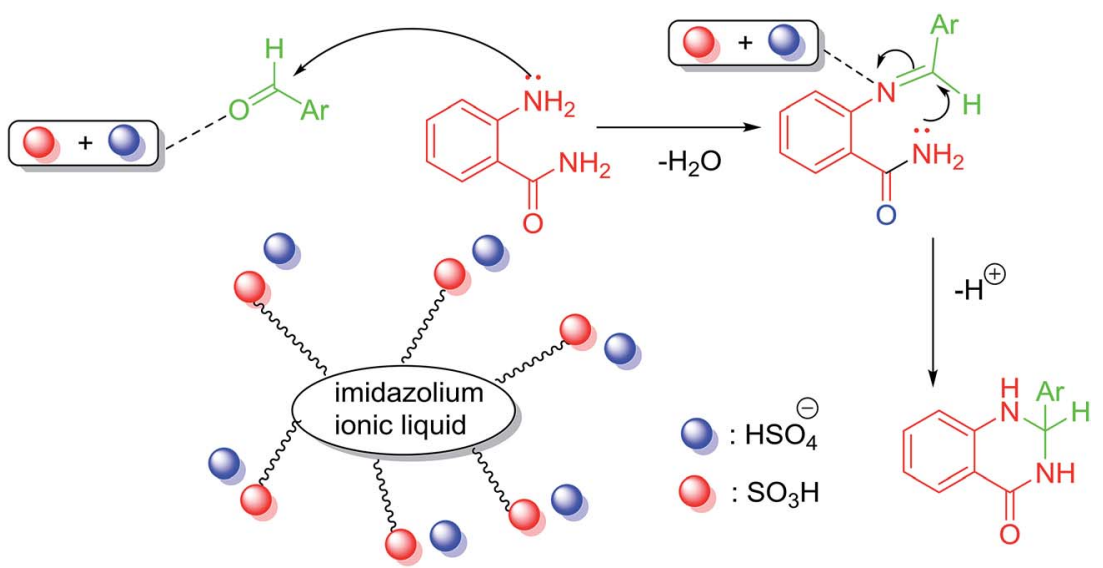

Scheme 4 A plausible mechanism for the synthesis of 2,3-dihydroquinazolin-4(1H)-one.

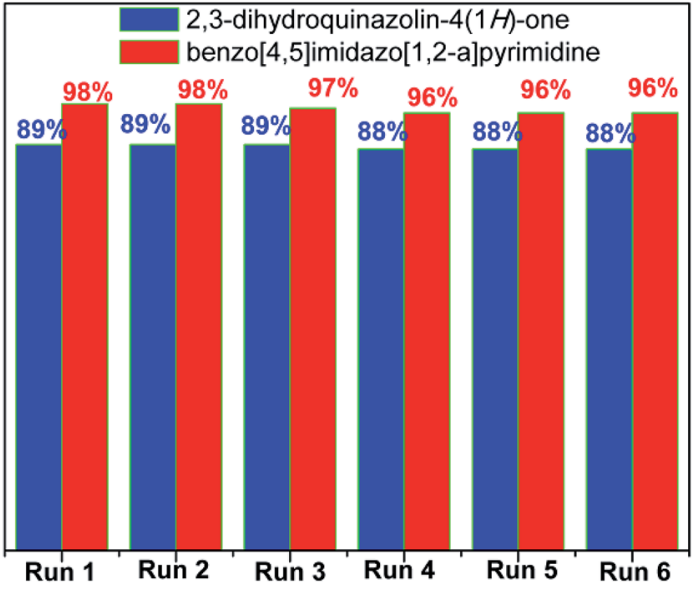

Fig. 1 Recycling test.

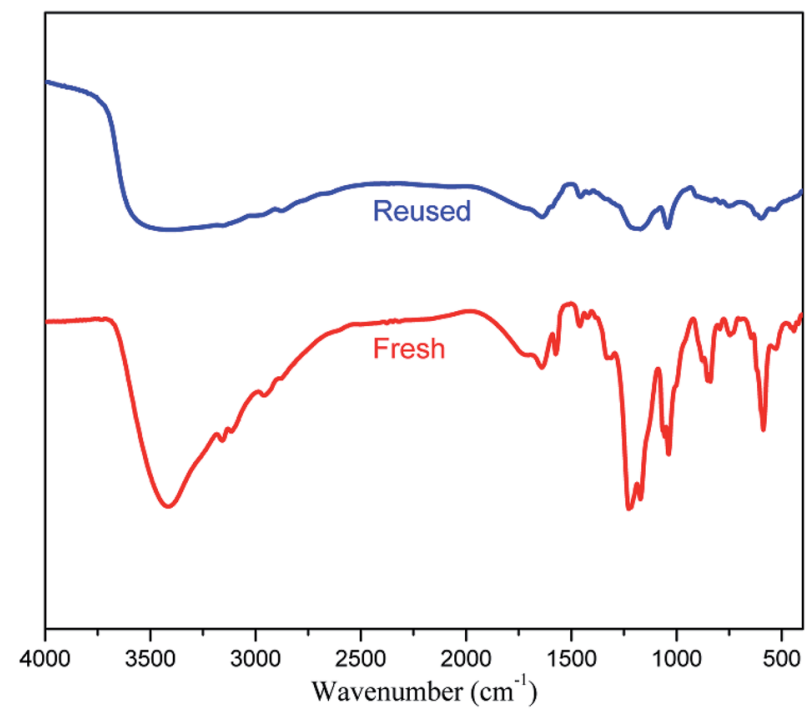

Fig. 2 FT-IR spectra of the fresh and the six-times reused catalyst.

\section{Conclusions}

We have developed a facile, efficient, and atom-economic method for preparing benzo[4,5]imidazo[1,2-a]pyrimidines and 2,3-dihydroquinazolin-4(1H)-ones under metal- and solvent-free conditions. The presented method provides a straightforward and green approach for the preparation of biologically nitrogen-heterocyclic compounds from the readily available starting materials in good to excellent yields within

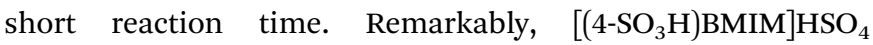
Brønsted acidic ionic liquid showed to be particularly suitable for these transformations as highlighted by its environmental friendliness, low-cost, recyclability, and simplicity of operation.

\section{Experimental}

\section{Materials and instrumentation}

All the reagents were purchased from Merck, Acros, and SigmaAldrich and used without further purification. Ultrasonic irradiation was performed in Elma sonic S30H. FT-IR spectra were analyzed using a Bruker Vertex 70 ( $\mathrm{KBr}$ pellets). Thermogravimetric analysis was performed on Analyzer TGA Q5000. ${ }^{1} \mathrm{H}$ and ${ }^{13} \mathrm{C}$ NMR spectra were performed on a Bruker Advance 500. High-resolution electrospray ionization mass spectrometry (HRMS-ESI) was performed on a Bruker micrOTOF-QII MS at $80 \mathrm{eV}$.

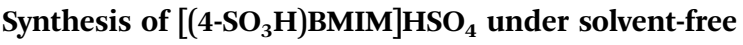 sonication}

[(4- $\left.\left.\mathrm{SO}_{3} \mathrm{H}\right) \mathrm{BMIM}\right] \mathrm{HSO}_{4}$ was synthesized via a one-pot two-step procedure under solvent-free sonication according to our previous literature report. ${ }^{22}$

General procedure for the synthesis of benzo[4,5]imidazo[1,2a]pyrimidines

A mixture of benzaldehyde (106 mg, $1 \mathrm{mmol}$ ), ethyl acetoacetate (130 mg, $1 \mathrm{mmol}$ ), 2-aminobenzimidazole $(133 \mathrm{mg}, 1 \mathrm{mmol})$ and $\left[\left(4-\mathrm{SO}_{3} \mathrm{H}\right) \mathrm{BMIM}^{2} \mathrm{HSO}_{4}(31.6 \mathrm{mg}, 0.1 \mathrm{mmol})\right.$ was heated $100{ }^{\circ} \mathrm{C}$ and the progress of the reaction was monitored by TLC. 
After completion of the conversion, the reaction mixture was quenched with cold ethanol $(10 \mathrm{~mL})$. The crude product was filtered and washed with petroleum ether $(10 \mathrm{~mL})$, and then purified by recrystallization from ethanol to obtain the desired pure product.

\section{General procedure for the synthesis 2,3-dihydroquinazolin- 4(1H)-one}

A mixture of anthranilamide (136 $\mathrm{mg}, 1 \mathrm{mmol})$, benzaldehyde (106 mg, $1 \mathrm{mmol})$, and [(4-SO $\left.{ }_{3} \mathrm{H}\right) \mathrm{BMIM}^{-} \mathrm{HSO}_{4}(31.6 \mathrm{mg}, 0.1$ $\mathrm{mmol}$ ) was sonicated for $30 \mathrm{~min}$ at room temperature and the progress of the reaction was monitored by TLC or GC-MS. After completion of the conversion, the reaction mixture was quenched with ethanol $(10 \mathrm{~mL})$. The crude product was filtered and washed with petroleum ether $(2 \times 5 \mathrm{~mL})$, and then purified by recrystallization from ethanol to afford the desired pure product.

\section{Conflicts of interest}

There are no conflicts to declare.

\section{Acknowledgements}

This research was funded by Viet Nam National University, Ho Chi Minh City (VNU-HCM) under grant number 562-2018-18-03.

\section{References}

1 V. I. Parvulescu and C. Hardacre, Chem. Rev., 2007, 107, 2615-2665.

2 M. Zhang, R. Ettelaie, T. Yan, S. Zhang, F. Cheng, B. P. Binks and H. Yang, J. Am. Chem. Soc., 2017, 139, 17387-17396.

3 Q. Hou, M. Zhen, L. Liu, Y. Chen, F. Huang, S. Zhang, W. Li and M. Ju, Appl. Catal., B, 2018, 224, 183-193.

4 T. Akiyama and K. Mori, Chem. Rev., 2015, 115, 9277-9306.

5 M. A. Martins, C. P. Frizzo, D. N. Moreira, N. Zanatta and

H. G. Bonacorso, Chem. Rev., 2008, 108, 2015-2050.

6 J. C. Schleicher and A. M. Scurto, Green Chem., 2009, 11, 694. 7 H. Olivier-Bourbigou, L. Magna and D. Morvan, Appl. Catal., A, 2010, 373, 1-56.

8 J. P. Hallett and T. Welton, Chem. Rev., 2011, 111, 3508-3576.

9 R. L. Vekariya, J. Mol. Liq., 2017, 227, 44-60.

10 A.-O. Diallo, G. Fayet, C. Len and G. Marlair, Ind. Eng. Chem. Res., 2012, 51, 3149-3156.

11 A. O. Diallo, C. Len, A. B. Morgan and G. Marlair, Sep. Purif. Technol., 2012, 97, 228-234.

12 A.-O. Diallo, A. B. Morgan, C. Len and G. Marlair, Energy Environ. Sci., 2013, 6, 699-710.

13 A. Bado-Nilles, A. O. Diallo, G. Marlair, P. Pandard, L. Chabot, A. Geffard, C. Len, J. M. Porcher and W. Sanchez, J. Hazard. Mater., 2015, 283, 202-210.

14 M. A. Martins, C. P. Frizzo, A. Z. Tier, D. N. Moreira, N. Zanatta and H. G. Bonacorso, Chem. Rev., 2014, 114, PR1-PR70.

15 A. S. Amarasekara, Chem. Rev., 2016, 116, 6133-6183.
16 A. C. Cole, J. L. Jensen, I. Ntai, K. L. T. Tran, K. J. Weaver, D. C. Forbes and J. H. Davis, J. Am. Chem. Soc., 2002, 124, 5962-5963.

17 H. Zhang, F. Xu, X. Zhou, G. Zhang and C. Wang, Green Chem., 2007, 9, 1208-1211.

18 J. Yang, H. Zhou, X. Lu and Y. Yuan, Catal. Commun., 2010, 11, 1200-1204.

19 J. Long, W. Lou, L. Wang, B. Yin and X. Li, Chem. Eng. Sci., 2015, 122, 24-33.

20 A. Wang, X. Zheng, Z. Zhao, C. Li, Y. Cui, X. Zheng, J. Yin and G. Yang, Appl. Catal., A, 2014, 482, 198-204.

21 Q. Peng, K. Mahmood, Y. Wu, Z. Liu, L. Wei, H. Yuan and R. Yang, Mol. Catal., 2017, 434, 140-145.

22 P. H. Tran, A.-T. Duy Nguyen, H. T. Nguyen and T. N. Le, RSC Adv. , 2017, 7, 54399-54406.

23 Q. T. Nguyen, A.-H. Thi Hang, T.-L. Ho Nguyen, D.-K. Nguyen Chau and P. H. Tran, RSC Adv., 2018, 8, 11834-11842.

24 P. H. Tran, X.-T. T. Nguyen and D.-K. N. Chau, Asian J. Org. Chem., 2018, 7, 232-239.

25 T. Raj, H. Sharma, Mayank, A. Singh, T. Aree, N. Kaur, N. Singh and D. O. Jang, ACS Sustainable Chem. Eng., 2017, 5, 1468-1475.

26 A. Shaabani, A. Rahmati and S. Naderi, Bioorg. Med. Chem. Lett., 2005, 15, 5553-5557.

27 W. Kong, Y. Zhou and Q. Song, Adv. Synth. Catal., 2018, 360, 1943-1948.

28 S. Tardy, A. Orsato, L. Mologni, W. H. Bisson, C. Donadoni, C. Gambacorti-Passerini, L. Scapozza, D. Gueyrard and P. G. Goekjian, Bioorg. Med. Chem., 2014, 22, 1303-1312.

29 R. Garamvolgyi, J. Dobos, A. Sipos, S. Boros, E. Illyes, F. Baska, L. Kekesi, I. Szabadkai, C. Szantai-Kis, G. Keri and L. Orfi, Eur. J. Med. Chem., 2016, 108, 623-643.

30 S. J. Kalita, D. Chandra Deka and H. Mecadon, RSC Adv., 2016, 6, 91320-91324.

31 K. B. Puttaraju, K. Shivashankar, Chandra, M. Mahendra, V. P. Rasal, P. N. Venkata Vivek, K. Rai and M. B. Chanu, Eur. J. Med. Chem., 2013, 69, 316-322.

32 T. H. Al-Tel and R. A. Al-Qawasmeh, Eur. J. Med. Chem., 2010, 45, 5848-5855.

33 M. Abedini, F. Shirini, M. Mousapour and O. Goli Jolodar, Res. Chem. Intermed., 2016, 42, 6221-6229.

34 I. M. Abbas, M. A. Abdallah, S. M. Gomha and M. S. H. Kazem, J. Heterocycl. Chem., 2017, 54, 3447-3457.

35 F. Bellina, R. Rossi, M. Lessi, C. Manzini and L. Perego, Synthesis, 2014, 46, 2833-2883.

36 C. Yao, S. Lei, C. Wang, T. Li, C. Yu, X. Wang and S. Tu, J. Heterocycl. Chem., 2009, 47, 26-32.

37 N. S. El-Gohary and M. I. Shaaban, Eur. J. Med. Chem., 2013, 63, 185-195.

38 M. Rawat and D. S. Rawat, Tetrahedron Lett., 2018, 59, 23412346.

39 M. V. Reddy, A. V. S. Reddy and Y. T. Jeong, Res. Chem. Intermed., 2016, 42, 4893-4906.

40 H. R. Shaterian, N. Fahimi and K. Azizi, Res. Chem. Intermed., 2013, 40, 1879-1898.

41 J. Liu, M. Lei and L. Hu, Green Chem., 2012, 14, 840-846. 
42 O. Rosati, M. Curini, F. Montanari, M. Nocchetti and S. Genovese, Catal. Lett., 2011, 141, 850-853.

43 A. M. Jadhav, Y. I. Kim, K. T. Lim and Y. T. Jeong, Tetrahedron Lett., 2018, 59, 554-557.

44 T. A. Shah, W. Raza, M. Muneer, N. A. Mir and M. Ahmad, ChemistrySelect, 2018, 3, 946-950.

45 A. Kamal, E. V. Bharathi, J. S. Reddy, M. J. Ramaiah, D. Dastagiri, M. K. Reddy, A. Viswanath, T. L. Reddy, T. B. Shaik, S. N. Pushpavalli and M. P. Bhadra, Eur. J. Med. Chem., 2011, 46, 691-703.

46 M. Rueping, A. P. Antonchick, E. Sugiono and K. Grenader, Angew. Chem., Int. Ed. Engl., 2009, 48, 908-910.

47 G. H. Zhang, J. M. Yuan, G. Qian, C. X. Gu, K. Wei, D. L. Mo, J. K. Qin, Y. Peng, Z. P. Zhou, C. X. Pan and G. F. Su, J. Med. Chem., 2017, 60, 6853-6866.

48 S. Y. Abbas, K. A. M. El-Bayouki, W. M. Basyouni and E. A. Mostafa, Med. Chem. Res., 2017, 27, 571-582.

49 D. Kumar, G. Mariappan, A. Husain, J. Monga and S. Kumar, Arabian J. Chem., 2017, 10, 344-350.

50 H. K. Kumara, R. Suhas, D. M. Suyoga Vardhan, M. Shobha and D. Channe Gowda, RSC Adv., 2018, 8, 10644-10653.

51 S. Poudapally, V. Gurram, R. Garlapati, C. Tulluri, U. Addepally, K. Vidya, S. Sharma, S. Sen and N. Pottabathini, J. Heterocycl. Chem., 2017, 54, 2272-2286.

52 A. A. Abdel-Aziz, L. A. Abou-Zeid, K. E. H. ElTahir, R. R. Ayyad, M. A. El-Sayed and A. S. El-Azab, Eur. J. Med. Chem., 2016, 121, 410-421.

53 A. A. Abdel-Aziz, L. A. Abou-Zeid, K. E. ElTahir, M. A. Mohamed, M. A. Abu El-Enin and A. S. El-Azab, Bioorg. Med. Chem., 2016, 24, 3818-3828.

54 M. Badolato, F. Aiello and N. Neamati, RSC Adv., 2018, 8, 20894-20921.
55 M. Dabiri, P. Salehi, M. Baghbanzadeh, M. A. Zolfigol, M. Agheb and S. Heydari, Catal. Commun., 2008, 9, 785-788.

56 M. Sharma, S. Pandey, K. Chauhan, D. Sharma, B. Kumar and P. M. Chauhan, J. Org. Chem., 2012, 77, 929-937.

57 V. F. Vavsari and G. M. Ziarani, Chem. Heterocycl. Compd., 2018, 54, 317-319.

58 D. He, M. Wang, S. Zhao, Y. Shu, H. Zeng, C. Xiao, C. Lu and Y. Liu, Fitoterapia, 2017, 119, 136-149.

59 U. Kshirsagar and R. Rohokale, Synthesis, 2016, 48, 12531268.

60 I. Khan, S. Zaib, S. Batool, N. Abbas, Z. Ashraf, J. Iqbal and A. Saeed, Bioorg. Med. Chem., 2016, 24, 2361-2381.

61 M. Zahedifard, F. L. Faraj, M. Paydar, C. Yeng Looi, M. Hajrezaei, M. Hasanpourghadi, B. Kamalidehghan, N. Abdul Majid, H. Mohd Ali and M. Ameen Abdulla, Sci. Rep., 2015, 5, 11544-11560.

62 J. Chen, W. Su, H. Wu, M. Liu and C. Jin, Green Chem., 2007, 9, 972-975.

63 J. Wang, Y. Zong, R. Fu, Y. Niu, G. Yue, Z. Quan, X. Wang and Y. Pan, Ultrason. Sonochem., 2014, 21, 29-34.

64 S. Nagarajan, T. M. Shaikh and E. Kandasamy, New J. Chem., 2015, 39, 9693-9699.

65 Y. Luo, Y. Wu, Y. Wang, H. Sun, Z. Xie, W. Zhang and Z. Gao, RSC Adv., 2016, 6, 66074-66077.

66 N. Azizi, F. Abbasi and M. Abdoli-Senejani, Mater. Chem. Phys., 2017, 196, 118-125.

67 L. Shiri, H. Narimani and M. Kazemi, Appl. Organomet. Chem., 2018, 32, e3999.

68 M. Rahman, I. Ling, N. Abdullah, R. Hashim and A. Hajra, RSC Adv., 2015, 5, 7755-7760.

69 N. Y. Kim and C.-H. Cheon, Tetrahedron Lett., 2014, 55, 23402344. 